Note

\title{
Antibacterial Compounds of Licorice against Upper Airway Respiratory Tract Pathogens
}

\author{
Yasuo TANAKA $^{1}$, Hiroe KikUZAKI ${ }^{2}$, Seiji FuKUdA ${ }^{1}$, and Nobuji NAKATANI ${ }^{2, *}$ \\ ${ }^{1} R$ \& D Laboratory, Taiyo Corporation, 1-6-27 Higashiawaji, \\ Higashiyodogawa, Osaka 533-0023, Japan \\ ${ }^{2}$ Division of Food and Health Science, Graduate School of Human Life Science, Osaka City University, \\ 3-3-138 Sugimoto, Sumiyoshi, Osaka 558-8585, Japan
}

(Received August 26, 2000)

\begin{abstract}
Summary The antibacterial activity of compounds obtained from licorice was measured against upper airway respiratory tract bacteria such as Streptococcus pyogenes, Haemophilus influenzae and Moraxella catarrhalis. Among the tested compounds, licoricidin exhibited the highest activity against all tested microorganisms with an MIC of $12.5 \mu \mathrm{g} / \mathrm{mL}$. Three coumarin derivatives, glycyrol, glycyrin and glycycoumarin also showed antibacterial activity.
\end{abstract}

Key Words licorice, Glycyrrhiza uralensis, antibacterial activity, upper airway respiratory tract pathogens

Licorice, Glycyrrhiza uralensis F., has been used as an important crude drug such as a pectoral, demulcent, emollient, antidote for poison, expectorant, cough cure and analgesic in ayurvedic and Chinese medicines for a long time. The main constituents of licorice, glycyrrhizin and glycyrrhetinic acid show several pharmacological activities such as anti-inflammatory, antiallergenic, antihepatotoxic and antiviral effects. The minor constituents of licorice are flavonoids, which have some biological and antioxidant properties (1-4). Demizu et al. (2) reported that glycycoumarin and licocoumarone inhibited the growth of gram-positive bacteria and yeasts. Some coumarin derivatives such as glycyrol and glycyrin exhibited strong antibacterial activity against Streptococcus mutans (3).

Though licorice has been used in pharyngeal therapy, few chemical and biological studies on its active constituents against upper airway respiratory tract bacteria have been carried out so far. In our preliminary screening for antibacterial herbs against upper airway respiratory tract bacteria, licorice showed the most potent activity among tested herbs. In this paper, we report the isolation and characterization of antibacterial compounds from licorice extract and their antibacterial effect against oropharyngeal microorganisms.

\section{Experimental}

Plant Material. Commercial samples of licorice (Glycyrrhiza uralensis F.) were purchased from Nippon Funmatu (Osaka, Japan).

Chemicals. Silica gel (300 mesh, Wako Pure Chemical Industries, Osaka, Japan) and Sephadex LH-20 (Pharmacia Biotec, Uppsala, Sweden) were used for column chromatography. Glycyrrhizin and gly-

\footnotetext{
* To whom correspondence should be addressed.
}

cyrrhetinic acid were obtained from Wako Pure Chemical Industries. Cetylpyridinium chloride monohydrate (CPC) was obtained from Wako Pure Chemical Industries.

Microorganisms and media. Streptococcus pyogenes (ATCC 12344), Haemophilus influenzae (ATCC 33391) and Moraxella catarrhalis (ATCC 25238) were obtained from the American Type Culture Collection (Summit Pharmaceuticals International, Tokyo, Japan). For the culture of $H$. influenzae, Haemophilus test medium (HTM) was used (5). HTM was prepared using MuellerHinton broth (Difco, Detroit, USA) as the base to which $10 \mu \mathrm{g}$ of hematin per $\mathrm{mL}$ and $10 \mu \mathrm{g}$ of $\beta$-nicotinamide adenine dinucleotide ( $\beta$-NAD) (Wako Pure Chemical Industries) per $\mathrm{mL}$ were added. $S$. pyogenes and $M$. catarrhalis were grown in media containing $1.0 \%$ glucose (Wako Pure Chemical Industries), 0.5\% bactopeptone (Difco) and 0.5\% yeast extract (Difco).

Thin-layer chromatography (TLC). TLC was performed on Merck silica gel TLC plates $60 \mathrm{~F}_{254}$ (Darmstadt, Germany) with benzene/acetone $(5 / 1, \mathrm{v} / \mathrm{v})$ or chloroform/ethyl acetate/formic acid (7/3/0.1, v/v/v), and visualized by UV irradiation (254 and 365 $\mathrm{nm})$.

Spectrophotometry. Bacterial growth was measured on the basis of turbidity using a Hitachi U-1100 spectrophotometer (Tokyo, Japan).

Mass spectrometry. EI-MS $(70 \mathrm{eV})$ and positive SIMS (matrix : glycerol) were measured on a Hitachi M2000 mass spectrometer.

Nuclear magnetic resonance spectrometry (NMR). The ${ }^{1} \mathrm{H}-\mathrm{NMR},{ }^{13} \mathrm{C}-\mathrm{NMR},{ }^{1} \mathrm{H}-{ }^{1} \mathrm{H}$ COSY, HMOC and HMBC spectra were recorded on a Varian U-500 spectrometer (Palo Alto, USA) $\left({ }^{1} \mathrm{H}\right.$ at $500 \mathrm{MHz}$ and ${ }^{13} \mathrm{C}$ at $125 \mathrm{MHz}$ ) using tetramethylsilane (TMS) as an internal standard.

Infrared spectrometry (IR). Infrared spectra were 
run on a Perkin-Elmer 1800 infrared spectrometer (Norwalk, USA).

Extraction of licorice. Dried ground roots $(200 \mathrm{~g})$ of licorice (Glycyrrhiza uralensis F.) were extracted at room temperature with $n$-hexane ( $1 \mathrm{~L} \times 3$ times), dichloromethane $(1 \mathrm{~L} \times 3$ times) and acetone/water $(7 / 3, \mathrm{v} / \mathrm{v})$ ( $1 \mathrm{~L} \times 3$ times), successively (each 3 days). The acetone/water extract was evaporated in vacuo to give a dark-brownish residue. Then the residue was partitioned with ethyl acetate ( $1 \mathrm{~L} \times 3$ times) and water. Ethyl acetate insoluble materials and water solution were combined and extracted with $n$-butanol ( $1 \mathrm{~L} \times 3$ times).

Isolation of licorice constituents. The dichloromethane extract which showed antimicrobial activity was subjected to silica gel column chromatography using chloroform and chloroform/ethyl acetate (19/1, $\mathrm{v} / \mathrm{v}$ ) as eluents. By further chromatography of these fractions over preparative TLC, eleven fractions (A-K) were obtained and each fraction eluted was examined for antibacterial activity. Each fraction was rechromatographed over Sephadex LH-20 using dichloromethane and over silica gel using benzene/acetone $(5 / 1, v / v)$, and then purified on silica gel preparative TLC eluted with benzene-acetone $(9 / 1, \mathrm{v} / \mathrm{v})$ to give compounds 1-5: licoricidin (1, $18 \mathrm{mg})(6)$, vestitol (2, $2 \mathrm{mg}$ ) (7), glycyrol (3, $2 \mathrm{mg})(8)$, glycyrin $(\mathbf{4}, 5 \mathrm{mg})(9)$ and glycycoumarin $(\mathbf{5}, 120 \mathrm{mg})(3)$.

Licoricidin (1): ${ }^{1} \mathrm{H}-\mathrm{NMR}\left(\mathrm{CDCl}_{3}\right): \delta_{\mathrm{H}} 1.76(3 \mathrm{H}, d$, $J=1.0 \mathrm{~Hz}), 1.79(3 \mathrm{H}, d, J=1.5 \mathrm{~Hz}), 1.82(3 \mathrm{H}$, br s $), 1.85$ $(3 \mathrm{H}$, br s), $2.79(1 \mathrm{H}, d d, J=10.0,16.0 \mathrm{~Hz}), 3.00(1 \mathrm{H}$, $d d d, J=2.0,5.0,16.0 \mathrm{~Hz}), 3.3-3.5(1 \mathrm{H}$, overlapping with isopentenyl moiety), $3.36(2 \mathrm{H}, d, J=6.0 \mathrm{~Hz}), 3.45$ $(2 \mathrm{H}, d, J=7.0 \mathrm{~Hz}), 3.70(3 \mathrm{H}, s), 4.00(1 \mathrm{H}, t, J=$ $10.0 \mathrm{~Hz}), 4.29(1 \mathrm{H}, d d d, J=2.0,3.0,10.0 \mathrm{~Hz}), 5.25$ $(1 \mathrm{H}, m), 5.35(1 \mathrm{H}, m), 6.21(1 \mathrm{H}, s), 6.37(1 \mathrm{H}, d$, $J=8.5 \mathrm{~Hz}), 6.84(1 \mathrm{H}, d, J=8.5 \mathrm{~Hz})$. EI-MS $m / z$ (rel. int): $424[\mathrm{M}]^{+}$(100), 221 (95), 165 (60), 132 (60).

The ethyl acetate extract was chromatographed on silica gel using benzene/acetone $(4 / 1, \mathrm{v} / \mathrm{v})$ to afford fractions $1-13$.

Fraction 2 (122 mg) was rechromatographed over silica gel using benzene/acetone $(9 / 1, \mathrm{v} / \mathrm{v})$ and then recrystallized from benzene to give liquiritigenin (6, $6 \mathrm{mg})(10)$.

Fraction 13 (40 mg) was rechromatographed over silica gel using benzene/acetone $(1 / 1, \mathrm{v} / \mathrm{v})$ and then recrystallized from benzene/acetone $(1 / 1, \mathrm{v} / \mathrm{v})$ to give liquiritin (7, $20 \mathrm{mg})(10)$.

Liquiritin (7): IR (Nujol) $v_{\max } \mathrm{cm}^{-1}: 3328,1649$, 1609. ${ }^{1} \mathrm{H}-\mathrm{NMR} \quad \delta_{\mathrm{H}}\left(\mathrm{CD}_{3} \mathrm{OD}\right): 2.73(1 \mathrm{H}, \quad d d, \quad J=2.2$, $17.0 \mathrm{~Hz}), 3.04(1 \mathrm{H}, d d, J=12.7,17.0 \mathrm{~Hz}), 3.40(1 \mathrm{H}, m)$, $3.44(2 \mathrm{H}, m), 3.46(1 \mathrm{H}, d d, J=3.5,8.5 \mathrm{~Hz}), 3.69(1 \mathrm{H}$, $d d, J=5.5,12.0 \mathrm{~Hz}), 3.89(1 \mathrm{H}, d d, J=2.5,12.0 \mathrm{~Hz})$, $4.93(1 \mathrm{H}, d, J=7.5 \mathrm{~Hz}), 5.45(1 \mathrm{H}, d d, J=2.2,12.7 \mathrm{~Hz})$, $6.36(1 \mathrm{H}, d, J=2.0 \mathrm{~Hz}), 6.50(1 \mathrm{H}, d d, J=2.0,8.5 \mathrm{~Hz})$, $7.14(2 \mathrm{H}, d, J=8.5 \mathrm{~Hz}), 7.44(2 \mathrm{H}, d, J=8.5 \mathrm{~Hz}), 7.72$ $(1 \mathrm{H}, d, J=8.5 \mathrm{~Hz}) .{ }^{13} \mathrm{C}-\mathrm{NMR} \delta_{\mathrm{C}}\left(\mathrm{CD}_{3} \mathrm{OD}\right): 45.0,62.5$, $71.3,74.9,78.0,78.2,80.7,102.2,103.8,111.8$, 115.0, 117.8 (2C), 128.8 (2C), 129.9, 134.4, 159.2, 165.4, 166.9, 193.2. SI-MS m/z: $419[\mathrm{M}+\mathrm{H}]^{+}, 257$.
Antibacterial assay. The minimum inhibitory concentration (MIC) was measured by the two-fold serial broth dilution method (11). The test sample was first dissolved in $99 \%$ ethanol at a concentration of $5 \%$. Two-fold dilutions of the test compounds were prepared using ethanol, and $80 \mu \mathrm{L}$ of each dilution was added to $10 \mathrm{~mL}$ of the liquid broth. The sample concentrations used for the assay were 200, 100, 50, 25, 12.5, and $6.25 \mu \mathrm{g} / \mathrm{mL}$. The highest concentration used for the assay was $400 \mu \mathrm{g} / \mathrm{mL}$ due to the solubility limitation of the samples in the water-based media. Fifty $\mu \mathrm{L}$ of the 3 to 4-day-old culture of the test microorganisms was then inoculated. It should be noted that the concentration of ethanol was always $0.4 \%$, which did not affect the growth of bacteria. The cultures were incubated at $37^{\circ} \mathrm{C}$ for $24 \mathrm{~h}$. Bacterial growth was expressed on the basis of the turbidity at $660 \mathrm{~nm}$. Because some compounds become turbid in culture media, bacterial growth was evaluated by the difference in the turbidity between $\mathrm{O}$ h and $24 \mathrm{~h}$. The MIC was defined as the lowest concentration of the test compound that demonstrated no growth. Each treatment was replicated at least twice and the average of the values was obtained.

\section{Results and Discussion}

Extraction from licorice

The air-dried, ground roots of licorice were exhaustively extracted with $n$-hexane, dichloromethane and acetone/water $(7 / 3, \mathrm{v} / \mathrm{v})$, successively. The acetone/ water extract was evaporated in vacuo, and the residue was partitioned into an ethyl acetate soluble fraction and a water-soluble fraction. The latter was further extracted with $n$-butanol.

Antibacterial activity of glycyrrhizin and glycyrrhetic acid

Licorice has been known to contain a large amount of glycyrrhizin and glycyrrhetic acid, accounting for its sweetness. Hattori et al. reported that glycyrrhetic acid showed antibacterial activity against $S$. mutans at the MIC of $100 \mu \mathrm{g} / \mathrm{mL}$, while glycyrrhizin did not show any activity (3). It is necessary to examine the antibacterial activity contribution of glycyrrhizin and glycyrrhetic acid against oropharyngeal bacteria. Therefore, an antibacterial test of these compounds was carried out. Glycyrrhizin and glycyrrhetic acid did not exhibit any activity against oropharyngeal bacteria at the concentration of $400 \mu \mathrm{g} / \mathrm{mL}$. Therefore glycyrrhizin and glycyrrhetic acid hardly seem responsible for the antibacterial activity of licorice extract.

\section{Isolation of the constituents of licorice}

The dichloromethane and ethyl acetate fractions exhibited antimicrobial activity. Then the dichloromethane fraction was subjected to silica gel column chromatography to afford eleven fractions (A-K). Most of the fractions showed antibacterial activity against upper airway respiratory tract bacteria. Above all, active fractions (C, D, F, H and $\mathrm{K}$ ) were purified by a combination of column chromatographies or recrystallization, to give five compounds, licoricidin (1), vestitol (2), glycyrol (3), glycyrin (4) and glycycoumarin (5). The ethyl acetate fraction was subjected to silica gel column 
<smiles>COc1cc2c(c(O)c1CC=C(C)C)CC(c1ccc(O)c(CC=C(C)C)c1O)CO2</smiles><smiles>COc1ccc(C2COc3cc(O)ccc3C2)c(O)c1</smiles><smiles>COc1c(CC=C(C)C)c(O)cc2oc(=O)c3c4ccc(O)cc4oc3c12</smiles><smiles>COc1cc2oc(=O)c(-c3ccc(O)cc3O)cc2c(OC)c1CC=C(C)C</smiles><smiles>COc1c(CC=C(C)C)c(O)cc2oc(=O)c(-c3ccc(O)cc3O)cc12</smiles>

Glycycoumarin (5)<smiles>[R]Oc1ccc(C2CC(=O)c3ccc(O)cc3O2)cc1</smiles>

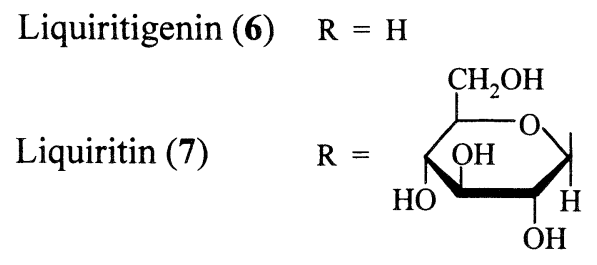

Fig. 1. Compounds isolated from licorice.

chromatography to afford fractions 1-13. These fractions were rechromatographed on silica gel (benzeneacetone) and then recrystallized from benzene and benzene/acetone $(1: 1, \mathrm{v} / \mathrm{v})$ to give compounds $(\mathbf{6})$ and $(\mathbf{7})$, respectively. These compounds were identified by IR, EIMS, ${ }^{1} \mathrm{H}-\mathrm{NMR}$ and ${ }^{13} \mathrm{C}-\mathrm{NMR}$ measurements $(3,6-10)$. Antibacterial activity of isolated compounds

The antibacterial activity of compounds 1-7 obtained from licorice was measured against the upper airway respiratory tract bacteria. Table 1 shows the minimum inhibitory concentrations (MICs) of the isolated compounds against three oropharyngeal bacteria. Among the tested compounds, a prenylated isoflavan, i.e. licoricidin (1) exhibited the highest activity with an MIC of $12.5 \mu \mathrm{g} / \mathrm{mL}$. Prenylated coumarin derivatives such as glycyrol (3), glycyrin (4) and glycycoumarin (5) also showed activity against upper airway respiratory tract bacteria, while liquiritigenin (6) and liquiritin
Table 1. MICs ${ }^{\mathrm{a}}$ of constituents against oropharyngeal bacteria from licorice.

\begin{tabular}{lccc}
\hline Substance & S. pyogenes & H. influenzae & M. catarrhalis \\
\hline Licoricidin (1) & $12^{\mathrm{b}}$ & 12 & 12 \\
Vestitol (2) & 50 & 100 & 100 \\
Glycyrol (3) & 50 & 100 & $>100$ \\
Glycyrin (4) & 25 & 25 & 50 \\
Glycycoumarin (5) & 25 & 25 & 100 \\
Liquiritigenin (6) & $>100$ & $>100$ & $>100$ \\
Liquiritin (7) & $>100$ & $>100$ & $>100$
\end{tabular}

a: MICs $(\mathrm{mg} / \mathrm{mL}) .{ }^{\text {b: }}$ : Levels assayed were 100, 50, 25, 12.5 and $6.25 \mu \mathrm{g} / \mathrm{mL}$.

(7), non-prenylated flavanones, were inactive. 3Arylcoumarins (3-5) were reported by Hattori et al. (3) to possess antibacterial activity against gram-positive 
bacteria such as Staphylococcus aureus and S. mutans, whereas they were inactive against gram-negative bacteria and fungi. Hatano et al. (12) have reported that 1 is ineffective against gram-negative bacteria such as $E$. coli. On the other hand, when tested against upper airway respiratory tract bacteria, these compounds (1, 3-5) showed antibacterial activity against both grampositive bacteria such as $S$. pyogenes and gram-negative bacteria such as $H$. influenzae and $M$. catarrhalis. In particular, among the separated compounds, 1 exhibited the highest activity against all the upper airway respiratory tract bacteria tested so far. Mitscher et al. (13) reported that the prenylated isoflavan compounds, hispaglabridin A and glabridin, possessed antibacterial activity against $S$. aureus, Mycobacterium smegmatis and Candida albicans. Demizu et al. reported that $\mathbf{5}$ showed antibacterial activity against $B$. subtilis, $S$. aureus and $S$. mutans (2). Hatano et al. (12) reported that the prenylated flavonoid compounds from licorice such as 3'-( $\gamma, \gamma$-dimethylallyl $)$-kjevitone, 8 - $(\gamma, \gamma$-dimethylallyl $)$ wigteone and isoangustone $\mathrm{A}$, showed strong antimicrobial activity against methicillin-resistant $S$. aureus (MRSA). In our research, 1 substituted by two prenyl groups also was more effective than 3-arylcoumarins (3-5). These results indicate that the prenyl groups play an important role in the antibacterial activity. Comparison of the antibacterial effect of isolated compounds with an antibacterial agent

Cetylpyridinium chloride (CPC), an antibacterial agent, is used in Japan for the sterilization in oral cavity and pharynx division. In a comparative antibacterial test of isolated compounds with $\mathrm{CPC}$ against $S$. pyogenes and $H$. influenzae, CPC showed higher activity with an MIC of $0.5-1 \mu \mathrm{g} / \mathrm{mL}$ than 1. Hatano et al. (12) reported that antibacterial activity was intensified by a combination of 1 and oxacillin, one of the antimicrobial agents, and that the mechanism of action was based on the catalytic function of penicillin-binding protein $2^{\prime}$. Therefore, 1 might show higher effectiveness when combined with some antibacterial agents.

Conclusion

The antibacterial activity of phenolic compounds from licorice was first studied against upper airway respiratory tract bacteria. Among the tested compounds, licoricidin (1) possessed the highest activity, followed by 3-arylcoumarins, glycyrol (3), glycyrin (4) and glycycoumarin (5).

\section{REFERENCES}

1) Okada K, Tamura Y, Yamamoto M, Inoue Y, Takagaki R, Takahashi K, Demizu S, Kajiyama K, Hiraga Y,
Kinoshita T. 1989. Identification of antimicrobial and antioxidant constituents from licorice of Russian and Xinjiang origin. Chem Pharm Bull (Tokyo) 37: 2528-2530.

2) Demizu S, Kajiyama K, Takahashi K, Hiraga Y, Yamamoto S, Tamura Y, Okada K, Kinoshita T. 1988. Antioxidant and antimicrobial constituents of licorice: Isolation and structure elucidation of a new benzofuran derivative. Chem Pharm Bull (Tokyo) 36: 3474-3479.

3) Hattori M, Miyachi K, Shu Y-Z, Kakiuchi N, Namba T. 1986. Studies on dental caries prevention by traditional medicines (IX) potent antibacterial action of coumarin derivatives from licorice roots against Streptococcus mutans. Shoyakugaku Zasshi 40: 406-412 (in Japanese).

4) Namba T, Tsunezuka M, Dissanayake DMRB, Pilapitiya U, Saito K, Kakiuchi N, Hattori M. 1985. Studies on dental caries prevention by traditional medicines (part VII) screening of ayurvedic medicines for anti-plaque action. Shoyakugaku Zasshi 39: 146-153 (in Japanese).

5) Brinkley AW, Huber TW. 1978. Method for evaluating broth culture media: Application to Haemophilus. J Clin Microbiol 8: 520-524.

6) Fukai T, Toyono M, Nomura T. 1988. On the structure of licoricidin. Heterocycles 27: 2309-2313.

7) Abe N, Sato H, Sakamura S. 1987. Antifungal stress compounds from adzuki bean, Vigna angularis, treated with Cephalosporium gregatum type B. Agric Biol Chem 51: 349-353.

8) Fukai T, Wang Q-H, Kitagawa T, Kusano K, Nomura T, Iitaka Y. 1989. Structures of six isoprenoid-substituted flavonoids, gancaonins F, G, H, I, glycyrol, and isoglycyrol from xibei licorice (Glycyrrhiza sp.). Heterocycles 29 : 1761-1772.

9) Kinoshita T, Saitoh T, Shibata S. 1978. A new 3-arylcoumarin from licorice root. Chem Pharm Bull (Tokyo) 26: 135-140.

10) Nakanishi T, Inada A, Kambayashi K, Yoneda K. 1985. Flavonoid glycosides of the roots of Glycyrrhiza uralensis. Phytochemistry 24: 339-341.

11) Muroi H, Kubo I. 1993. Combination effects of antibacterial compounds in green tea flavor against Streptococcus mutans. J Agric Food Chem 41: 11021105.

12) Hatano T, Shintani $Y$, Aga $Y$, Shiota S, Tsuchiya T, Yoshida T. 2000. Phenolic constituents of licorice. VIII. Structure of glicophenone and glicoisoflavanone, and effects of licorice phenolics on methicillin-resistant Staphylococcus aureus. Chem Pharm Bull (Tokyo) 48 : 1286-1292.

13) Mitscher LA, Park YH, Omoto S, Clark GW, Clark D. 1978. Antimicrobial agents from higher plants, Glycyrrhiza glabra L. (var. Spanish). I. Some antimicrobial isoflavans, isoflavenes, flavanones and isoflavones. Heterocycles 9: 1533-1538. 